\title{
O comportamento dos laringectomizados frente à imagem corporal*
}

\author{
The behavior of laryngectomees in respect to their body image
}

\author{
Sabrina Hannickel, ${ }^{1}$ Márcia Maria Fontão Zago, ${ }^{2}$ Cláudia B dos Santos Barbeira ${ }^{3} \mathrm{e}$ \\ Namie Okino Sawada
}

\begin{abstract}
Resumo
0 objetivo deste estudo foi avaliar o comportamento do laringectomizado total frente à sua imagem corporal. O s dados foram coletados entre 15 pacientes, por meio de um instrumento que focalizou a descrição das características sociais dos sujeitos e frases afirmativas, com respostas de concordância ou discordância. As frases relacionavam-se a atitudes positivas ou negativas, de acordo com a percepção do paciente da sua imagem corporal alterada. Os participantes foram na maioria do sexo masculino (87\%), com média de idade de 60 anos, casados (80\%), aposentados (60\%) ou desempregados (27\%), com média de tempo de cirurgia de 2 anos, e $60 \%$ comunicam-se pela mímica labial. o comportamento identificado dos pacientes, mostrou que eles se ol ham no espelho (93\%), evitam tocar a área operada (73\%), sentem-se mais velhos (80\%), gostam da sua aparência (100\%), cuidam-se melhor (73\%) e são mais atentos com o corpo (87\%). O s resultados mostraram que as atitudes dos pacientes são contraditórias: as atitudes negativas refletem o conflito em lidar com a nova imagem e as atitudes positivas relacionam-se com o cuidado com o corpo e com a saúde. Frente às implicações dessas atitudes para a qualidade de vida do paciente, destacamos a importância de um programa de reabilitação eficaz antes e após a cirurgia, focalizando a imagem corporal alterada entre os seus objetivos.
\end{abstract}

Palavras-chave: laringectomia; imagem corporal; reabilitação; pacientes; psicologia; autoimagem; ajustamento social.

\footnotetext{
*Trabalho apresentado no XV Congresso Brasileiro de Cancerologia, Salvador - BA, novembro/2000. Financiado pelo CN Pq - processo n. 520604/96-2.

${ }^{1}$ Aluna do Curso de Graduação em Enfermagem da Escola de Enfermagem de Ribeirão Preto-USP. Bolsista de iniciação científica do CN Pq.

${ }^{2}$ Enfermeira. Professora Associada da Escola de Enfermagem de Ribeirão Preto-USP. Enviar correspondência para

M .M .F.Z. Escola de Enfermagem de Ribeirão Preto, Universidade de São Paulo, Av. dos Bandeirantes 3900; 14090 -

902 Ribeirão Preto, SP - Brasil.

${ }^{3}$ Estatística. Professora D outora da Escola de Enfermagem de Ribeirão Preto-USP.

${ }^{4}$ Enfermeira. Professora D outora da Escola de Enfermagem de Ribeirão Preto-USP.

Recebido em fevereiro de 2001.
} 


\begin{abstract}
This study aims at evaluating the behavior of total laryngectomees about their body image. $D$ ata were collected among 15 patients by means of an instrument that focused on the description of the social characteristics of the subjects and affirmative sentences, with agreement and disagreement responses, in relation to the attitudes as to their altered body image. The participants were mostly males $(87 \%), 60$ years old in average, married $(80 \%)$, retired $(60 \%)$ or unemployed $(27 \%)$. The surgery had been performed, in average, 2 years before, and $60 \%$ communicated by labial miming. The patients' attitudes showed that they look at themselves in the mirror $(93 \%)$, avoid touching the operated area (73\%) and are more attentive to their bodies (87\%). The results showed that the patients' attitudes are conflicting: the negative attitudes reflect the difficulties of coping related to the altered image, whereas the positive attitudes relate with body and health care. As consequence of these attitudes for the patients' quality of live, we emphasize the importance of an effective rehabilitation program before and after the surgery, that includes the coping with the altered body image among its objectives.
\end{abstract}

Key words laryngectomy; body image; rehabilitation; patients, psychology; self concept; social adjustment.

\section{INTRODUÇÃO}

Com a preocupação de estudar as características da reabilitação do laringectomizado, foi criado o Grupo de Apoio e Reabilitação da Pessoa O stomizada (GARPO) Laringectomizados, em 1990. Esse grupo é formado por profissionais da Escola de Enfermagem de Ribeirão Preto - USP e Hospital das Clínicas da Faculdade de $M$ edicina de Ribeirão Preto - U SP, abrangendo enfermeiros (docentes e assistenciais), alunos de enfermagem, fonoaudióloga e assistente social, com objetivos que visam à assistência, ao ensino e à pesquisa sobre a reabilitação dos laringectomizados.

Como integrantes do GARPOLaringectomizados, consideramos que dentre as diferentes dimensões da reabilitação do câncer e das mutilações dos procedimentos terapêuticos, a alteração da imagem corporal do paciente é uma questão ainda pouco compreendida.

0 câncer delaringeéum dos mais comuns a atingir a região da cabeça e pescoço, representando $25 \%$ dos tumores malignos que acometem essa área e $2 \%$ de todas as doenças malignas. ${ }^{1}$ A American Cancer Society (ACS) ${ }^{2}$ estima que durante 0 ano de 1999, 10.600 novos casos de câncer de laringe foram diagnosticados e 4.200 pessoas morreram desta doença. Esses dados demonstram a importância do câncer de laringe como problema de saúde pública no contexto nacional e mundial. A prevalência mundial do câncer de laringe é maior na população masculina, numa razão de 5:1, e a incidência aumenta acentuadamente após a idade de 50 anos. $^{2}$

0 tratamento para o câncer de laringe exige diferentes intervenções terapêuticas dependendo do estadiamento do tumor do paciente, destacando-se a cirurgia seguida de tratamento radioterápico e quimioterápico, - que provoca alterações fisiológicas e psicossociais para o paciente. D e modo geral, os procedimentos cirúrgicos realizados para a remoção do tumor e os outros procedimentos terapêuticos associados geram mutilações temporárias ou definitivas para o paciente.

$\mathrm{N}$ a literatura médica e de enfermagem, $\mathrm{O}$ tema da imagem corporal do laringectomizado é pouco estudado e nessa perspectiva propusemos este estudo com o objetivo de "avaliar o comportamento do laringectomizado com a sua imagem corporal".

\section{A LARINGECTOMIA TOTAL}

As pessoas com câncer de laringe em estágio III eIV submetem-seao procedimento 
cirúrgico denominado laringectomia total, para a erradicação do tumor. Em geral, a cirurgia é associada à ressecção cervical ganglionar para assegurar a extirpação total do tumor. A radioterapia e a quimioterapia também são indicações terapêuticas, podendo ocorrer antes ou depois da cirurgia, de acordo com a indicação médica. ${ }^{3}$

$\mathrm{N}$ a laringectomia total são removidas as estruturas que produzem o som laríngeo, ou seja, o seu esqueleto cartilaginoso (as pregas ou cordas vocais) e os músculos vizinhos. $A$ parte superior da faringe é suturada à base da língua e a traquéia é suturada à pele da base do pescoço, onde é realizada uma abertura, isto é, a traqueostomia.

Com a traqueostomia, o indivíduo perde a capacidade de emissão do som laríngeo (afonia) e tem sua imagem corporal alterada.

Assim, esses procedimentos terapêuticos são altamente mutilatórios pois acarretam alterações fisiológicas (alteração da via respiratória, traqueostomia permanente, afonia, diminuição da atividade motora do ombro e do pescoço, diminuição do olfato e do paladar) e psicossociais (alteração da imagem corporal, da comunicação, das atividades cotidianas e profissionais e da autoestima da pessoa). ${ }^{4}$ Desse modo, as conseqüências das terapêuticas atingem 0 indivíduo como um todo, exigindo atenção e qualidade do cuidado de enfermagem para a promoção da reabilitação.

\section{A IMAGEM CORPORAL NORMAL E ALTERADA}

A imagem corporal éum conceito abstrato que todo ser humano possui, porém, nem sempre é reconhecido. ${ }^{5}$

Todos os pacientes que são submetidos a uma cirurgia sofrem alguma alteração na imagem corporal; a cicatriz cirúrgica é uma forma dessa apresentação. Assim, pode-se dizer que a cicatriz é a característica definidora para se rotular um paciente como cirúrgico e, conseqüentemente, para caracterizá-lo como tendo uma imagem corporal alterada. $\mathrm{N}$ o caso do paciente submetido à laringectomia total, a percepção da mudança da imagem corporal é vista pela presença da traqueostomia definitiva e das seqüelas da ressecção ganglionar cervical.

A imagem corporal (IC) é definida como sendo 0 que nós sentimos e pensamos sobre o nosso corpo e nossa aparência corporal. A IC podeser compreendida por três elementos: 0 modo pelo qual percebemos e sentimos 0 nosso corpo (realidade do corpo), como o nosso corpo responde ao nosso comando (apresentação do corpo), e o padrão internalizado pelo qual os dois aspectos anteriores são julgados (ideal do corpo). ${ }^{5}$

0 termo imagem corporal alterada (ICA) refere-se a qualquer alteração significativa na IC que ocorre fora dos domínios do desenvolvimento. Entretanto, a definição da nova imagem, pelo indivíduo, dependerá de suas experiências, da adaptação a ela e da IC normal. Quanto mais flexível for a personalidade do indivíduo, mais fácil será a adaptação a ICA. ${ }^{5}$

0 modo como o indivíduo reagirá à ICA dependerá dos seguintes fatores: das estratégias de enfrentamento, da origem da alteração, da importância da nova imagem para o futuro do paciente, dos tipos e possibilidades de apoio que o paciente pode receber enquanto ajusta-se à nova imagem do corpo. As respostas do indivíduo à ICA podem variar: alguns negam o problema ou negligenciam a sua importância; outrostentam compartilhar o problema com amigos e familiares e desenvolvem estratégias positivas. ${ }^{5} \mathrm{O} \mathrm{s}$ sentimentos e as atitudes relacionadas à IC formam um conceito de corpo fundamental para uma vida social adequada, pois, a IC é um aspecto central da auto-estima de qualquer indivíduo.

A percepção da ICA pelo laringectomizado pode gerar um impacto psicossocial e atitudes que dificultam a reabilitação do paciente, favorecendo o seu isolamento social, a depressão e dificuldades gerais para o retorno aos papéis sociais. Assim, a identificação dessas atitudes é um aspecto importante para os enfermeiros que planejam a assistência.

É necessário esclarecer que, para os pesquisadores, a atitude é o modo de proceder ou agir, é uma reação ou maneira de ser em relação a uma determinada pessoa, objeto e situação. ${ }^{6}$ Portanto, cada laringectomizado terá uma atitude frente à nova imagem corporal e um novo modo de enfrentar essa 
situação. Essas atitudes são dinâmicas e podem ser modificadas durante o processo de reabilitação.

Ao buscar avaliar as atitudes dos laringectomizados frente à sua ICA, focalizamos gerar bases para melhor assistir a reabilitação do paciente.

\section{METODOLOGIA}

0 trabalho foi desenvolvido com 15 laringectomizados totais, participantes do GARPO-Laringectomizados, no período de agosto a dezembro de 1999. O s critérios de inclusão no estudo foram: serem maiores de 18 anos, sentirem-se em boas condições fisiológicas, terem realizado a cirurgia há mais de seis meses e concordarem em participar. 0 período de seis meses de cirurgia foi considerado como um tempo mínimo para um paciente vivenciar o impacto da ICA nas suas relações sociais. ${ }^{7}$

A coleta de dados foi realizada utilizandose um instrumento composto de duas partes: a) a primeira relaciona-se à descrição das características sociais dos sujeitos; b) a segunda parte é elaborada com frases afirmativas que pressupõem respostas fechadas de concordância ou discordância, mutuamente exclusivas, referentes às atitudes com a imagem corporal alterada, adaptado do instrumento elaborado por Gamba et al, ${ }^{7}$ para a mesma finalidade. Esse instrumento é composto por sete frases afirmativas relacionadas a atitudes possíveis, positivas ou negativas, de pacientes submetidos a cirurgias mutilatórias da especialidade de cabeça e pescoço, frente à sua IC.

As afirmações referentes às atitudes com a imagem corporal foram traduzidas da língua inglesa para a portuguesa. 0 instrumento foi encaminhado a três pesquisadores que fizeram a validação aparente de conteúdo das frases, ou seja, avaliaram a clareza e a adequação dos itens e se eles alcançam o objetivo proposto. 0 s juízes recomendaram alterações na redação de duas frases, o que foi acatado. A seguir, realizamos um teste piloto aplicando 0 instrumento com quatro laringectomizados que não participaram da amostra. Após, os itens do instrumento foram considerados claros e não houve necessidade de outras modificações.

A aplicação do instrumento ocorreu após as reuniões do grupo e no domicílio dos sujeitos.

O s resultados foram analisados pelo teste estatístico não paramétrico denominado Teste Binomial ${ }^{8} \mathrm{e}$ todas as afirmativas tiveram 0 mesmo peso.

Com a finalidade de explicitar a relação das afirmações com a atitude esperada, cada frase foi acompanhada de um valor positivo (+) ou negativo (-). Assim, a concordância para uma frase acompanhada do sinal ( + ) implica em uma atitude positiva e vice-versa. As seguintes frases foram consideradas como atitudes positivas: eu me sinto atraente, eu gosto da minha aparência física, eu cuido melhor de mim e eu estou mais atento(a) com o meu corpo; as atitudes consideradas negativas foram: eu evito tocar a área operada, eu evito olhar no espelho e eu me sinto mais velho(a).

0 estudo foi aprovado por um Comitê de Ética em Pesquisa e antes da aplicação do instrumento foram consideradosos princípios éticos. Todos os sujeitos assinaram o termo de consentimento informado e esclarecido.

\section{RESULTADOS E DISCUSSÃO}

A média do tempo de pós-cirurgia é de 2 anos e o desvio padrão é de 1 ano e 5 meses; $67 \%$ dos pacientes fizeram tratamento radioterápico após a cirurgia e apenas 1 (7\%) paciente submeteu-se à quimioterapia póscirúrgica. N o momento da coleta de dados, todos já tinham terminado essas modalidades de tratamento.

A média de idade para o grupo estudado é de 60 anos, com desvio padrão de 6,8 anos. Em relação ao gênero, $87 \%$ dos sujeitos são do sexo masculino. Essas características correspondem às apresentadas por $\mathrm{G}$ amba et al, ${ }^{7}$ para os pacientes com câncer de laringe, com desfiguramento extensivo.

Em relação à comunicação, $60 \%$ dos sujeitos expressam-se pela mímica labial e $40 \%$ utilizam a voz esofágica. Consideramos que a mímica labial é um processo de comunicação mais fácil de ser aprendido do que o da voz esofágica, porém, não é o mais natural. D e certa forma, percebemos que 
frente às dificuldades para a emissão da voz esofágica, há uma acomodação dos pacientes com a mímica labial. Behulau e Ziemer ${ }^{9}$ afirmam que, superado os problemas fisiológicos que podem impedir a emissão da voz esofágica, é desejável algumas características de personalidade do paciente como extroversão, motivação, persistência, auto-imagem positiva, sociabilidade, apoio familiar e interesse em se comunicar.

Q uanto ao estado civil, $80 \%$ dos pacientes são casados. Entretanto, o fato de serem casados não implica uma efetiva rede familiar de apoio, visto que o alcoolismo era um hábito comum aos pacientes, no período anterior à cirurgia, acarretando distúrbios familiares. Por outro lado, a comunicação pela mímica labial também dificulta 0 relacionamento familiar e social. ${ }^{4}$

Dos 15 sujeitos do estudo, 60\% estão aposentados e $27 \%$ desempregados. Em um estudo anterior, ${ }^{4}$ identificamos que a aposentadoria entre os laringectomizados não é planejada e é incentivada pela família, como uma atitude de superproteção.

Em relação à religião, $73 \%$ responderam que seguem a religião católica. O itenta por cento $(80 \%)$ dos pacientes têm formação educacional fundamental, sendo incompleta em 53\% deles. Essas duas características sociais estão inter-relacionadas. G randaCameron ${ }^{10}$ refere que a crença religiosa e 0 baixo nível sócio-econômico-educacional dos pacientes oncológicos latinos determinam significados para o processo de adoecer e de sobreviver ao câncer. Esses significados implicam em atribuições de causalidades exógenas (como a D eus, aos conflitos familiares) e endógenas (como a vulnerabilidade física pela idade cronológica). Esses significados foram também identificados por Schulze, ${ }^{11}$ que estudou as representações sociais de pacientes oncológicos brasileiros. É importante salientar que esses significados precisam ser compreendidos no contexto global de vida dos pacientes e não simplesmente criticados, pois, levam a atitudes passivas e a não adesão ao tratamento.

As características sociais dos laringectomizados são importantes de serem descritas, pois, elas influenciam as suas percepções e as atitudes com a ICA. ${ }^{5}$
A Tabela 1 apresenta a distribuição dos sujeitos participantes do estudo, segundo as suas características sociais.

Tabela 1. Distribuição dos pacientes segundo as suas características sociais.

\begin{tabular}{|c|c|c|}
\hline Ca racteríticas $5 \alpha$ iais & $n=15$ & 8 \\
\hline $\begin{array}{l}\text { Sewo } \\
\text { Masculino } \\
\text { Feminino } \\
\text { Estado civil } \\
\text { Casado } \\
\text { Soltein } \\
\text { Atividade profissional } \\
\text { Ativos } \\
\text { Aposentados } \\
\text { Derempregados } \\
\text { Religia } \\
\text { Catrica } \\
\text { Outras }\end{array}$ & $\begin{array}{c}13 \\
2 \\
12 \\
3 \\
2 \\
9 \\
4 \\
11 \\
4\end{array}$ & $\begin{array}{l}87 \\
13 \\
80 \\
20 \\
13 \\
60 \\
27\end{array}$ \\
\hline $\begin{array}{l}\text { Fomajaio educacional } \\
\text { Fundamental } \\
\text { complet } \\
\text { incomplets } \\
\text { Medio } \\
\text { complet } \\
\text { analfabet }\end{array}$ & $\begin{array}{l}4 \\
8 \\
1 \\
2\end{array}$ & $\begin{array}{c}27 \\
53 \\
7 \\
13\end{array}$ \\
\hline
\end{tabular}

Para análise estatística da significância das respostas obtidas na parte $B$ do instrumento, foi realizado o Teste Binomial, devido à sua natureza (respostas dicotômicas: "sim" ou "não") e ao pequeno número de sujeitos. 0 nível de significância utilizado foi $\alpha=0,05$.

A Tabela 2 apresenta as respostas de concordância para as afirmações relacionadas às atitudes frente à IC dos sujeitos, após a cirurgia, seguido de sua significância.

Para a maioria dos sujeitos deste estudo, a atitude de olhar-se no espelho é positiva $(93 \% ; p=0,004)$, porém, existe uma forte evidência de que a maioria evita tocar a área operada ( $73 \% ; p=0,059)$. D urante o período de internação e nas reuniões grupais pósoperatórias do GARPO, os pacientes são estimulados a realizar a avaliação da região operada, em frente a um espelho, observando e palpando o pescoço, para identificar precocemente qualquer sinal indicativo de complicação. As atitudes destes pacientes deixam claro que a avaliação realizada éparcial e insuficiente para alcançar a sua finalidade. Por outro lado, o fato de ol harem-se no espelho reflete uma atitude positiva para lidar com a ICA.

$N$ ove pacientes $(60 \%)$ sentem-se atraentes e apenas $6(40 \%)$ não, diferença não 
estatisticamente significativa ( $p=0,304)$. 0 sentimento de sentir-se mais velho(a) foi afirmado por $80 \%$ dos sujeitos $(p=0,018)$ e $100 \%(p=0)$ afirmaram que gostam da sua aparência. Esses resultados refletem que as atitudes dos laringectomizados com sua ICA são contraditórias. Considerando-se que a laringectomia total é mutilante, as atitudes positivas em relação à atração física e à apreciação da ICA demonstram que os pacientes estão, pelo menos, tentando enfrentar o problema. Price ${ }^{5}$ relata que a atração física é um aspecto fundamental para as relações sociais dos indivíduos, um estereótipo que opera em todos os níveis sociais.

Porém, essas atitudes chocam-se com a obtida para 0 aspecto de sentirem-se mais velhos, que foi afirmado pela maioria dos pacientes, refletindo a percepção da perda da vitalidade, do vigor físico e psicológico, após a cirurgia. Concordamos com $\mathrm{G}$ amba et al ${ }^{7}$ que relatam que o estigma do câncer leva a esse tipo de atitude, pois a cronicidade da doença, o tratamento mutilatório e a constante incerteza da cura influenciam a auto-estima e a idealização da IC.

Por outro lado, os resultados apontam para atitudes positivas quanto ao cuidado geral da saúde e com o corpo, após a cirurgia. Setenta e três por cento $(73 \%)$ dos pacientes $(p=$ $0,059)$ afirmaram que se cuidam melhor e $87 \%$ estão mais atentos com o seu corpo. Encontramos aqui outra contradição entre os pacientes que fizeram essas afirmações e que também afirmaram que não tocam a área operada. Porém, mesmo havendo atitudes contraditórias em relação à ICA, apreendemos que elas não impedem que os sujeitos implementem algumas ações de autocuidado com a saúde.

$Q$ uando relacionamos os nossos resultados com 0 estudo de $\mathrm{G}$ amba et al, ${ }^{7}$ que foi mais amplo, encontramos resultados semelhantes, mas com outros valores numéricos. 0 estudo desses autores envolveu um grupo de 42 laringectomizados totais; destes, 20\% não tocavam a área operada, 30\% não olhavam a área operada, 48\% não se sentiam atraentes, $33 \%$ afirmaram que se sentiam mais velhos e $30 \%$ apresentavam dificuldades severas de ajustamento social mesmo após quatro anos de cirurgia.
Tabela 2. Respostas concordantes com as frases afirmativas relacionadas com as atitudes frente à imagem corporal dos sujeitos, após a laringectomia total.

\begin{tabular}{|c|c|c|c|}
\hline Fase afirma tivas & $\mathrm{H}$ & Th & $\mathrm{P}^{+}$ \\
\hline 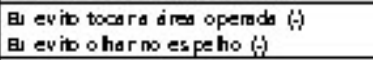 & $\begin{array}{c}11 \\
1\end{array}$ & $\begin{array}{l}7 \text { 象 } \\
7 \%\end{array}$ & $\begin{array}{l}0,050^{-} \\
0,004^{-}\end{array}$ \\
\hline 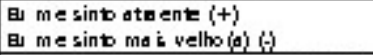 & $\stackrel{0}{12}$ & $\begin{array}{l}60 \% \\
80 \%\end{array}$ & $\begin{array}{c}16 \\
0,018\end{array}$ \\
\hline 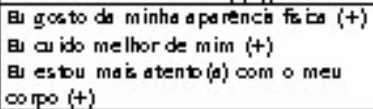 & $\begin{array}{l}15 \\
11 \\
13\end{array}$ & $\begin{array}{c}100 \% \\
7 \text { m } \\
8 \pi \%\end{array}$ & $\begin{array}{l}0,05 \\
0,05 \\
0,004\end{array}$ \\
\hline
\end{tabular}

*p: valor da probabilidade associada à estatística do Teste Binomial;8 N S: não significativo; **: resultado estatisticamente significativo; $\mathrm{N}$ : número de respostas concordantes, $(+)$ : atitude positiva; (-): atitude negativa.

Considerando que a média de período pós-operatório para os sujeitos do nosso estudo é de dois anos, concordamos com os autores acima citados que concluem que 0 aumento gradual no número de anos póscirurgia não corresponde à redução do sofrimento.

$\mathrm{N}$ a revisão de estudos que focalizaram as conseqüências da ICA para a vida do laringectomizado, realizada por $\mathrm{G}$ amba et al, ${ }^{7}$ os autores encontraram: reações de baixa autoestima e isolamento social; medo de rejeição e abandono; sentimento de ser deficiente e tendência suicida entre os pacientes laringectomizados.

0 baixo nível sócio-econômicoeducacional, a religião, a aposentadoria e o desemprego, a falta de uma efetiva rede de apoio familiar devido ao alcoolismo e ao insucesso com a reabilitação vocal podem ser barreiras para atitudes mais positivas para 0 enfrentamento da ICA. Concordamos com Price ${ }^{5}$ e $\mathrm{G}$ amba et al ${ }^{7}$ que consideram que as atitudes de reação à IC A dependerão das suas estratégias de enfrentamento, da origem da alteração, da importância da nova imagem para o futuro, dos tipos de apoio que ele pode receber enquanto ajusta-se à nova imagem do corpo. Para os autores, quanto mais flexível for a personalidade do indivíduo, mais fácil será a sua adaptação a ICA.

Frente aos resultados obtidos, consideramos que os laringectomizados convivem com a desfiguração considerando-a algo inevitável. As atitudes dos laringectomizados frente à sua ICA demonstram que não há adaptação e sim uma tentativa de conviver passivamente com a condição de perdas de papéis e da imagem ideal de corpo. Ter sobrevivido à doença estigmatizada, ao câncer 
e à cirurgia, são aspectos mais importantes do que a ICA. Esses resultados também se relacionam com os obtidos por Pedrolo e $\mathrm{Zago}^{12}$ que descreveram 0 enfrentamento à ICA pelo laringectomizado como um processo de resignação.

\section{CONSIDERAÇÕES FINAIS}

A ICA é um fator fundamental para a reabilitação e qualidade de vida dos laringectomizados.

As atitudes dos laringectomizados frente à sua ICA, avaliadas neste estudo, demonstram uma convivência contraditória com a condição. Ao mesmo tempo em que afirmam que se olham no espelho, gostam da sua aparência, se cuidam melhor esão mais atentos com o corpo, apresentam atitudes que denotam dificuldades em lidar com a ICA, como evitar tocar a área operada e sentirem-se mais velhos. Essas atitudes contraditórias podem prejudicar o processo de reabilitação dos pacientes, visto que geram compor-tamentos de baixa autoestima, isolamento social e dificuldades nos relacionamentos sociais. Contribuem para essas atitudes os significados culturais do paciente em relação à doença, à sua idade e às suas características sociais.

Portanto, na tentativa de favorecer 0 desenvolvimento de atitudes positivas entre os laringectomizados para lidarem com a sua ICA, é de fundamental importância a elaboração de programas de reabilitação. Esses programas devem se iniciar no momento do conhecimento do diagnóstico pelo paciente e continuar até o pós-operatório, e contar com a inserção da família. Precisamos compreender que lidar com a ICA é sempre um processo cíclico de atitudes contraditórias que demonstram a fragilidade emocional e social dos pacientes frente à situação pela qual passam e que exige apoio e intervenção profissional.

\section{REFERÊNCIAS BIBLIOGRÁFICAS}

1. Instituto $\mathrm{N}$ acional de $\mathrm{C}$ âncer (Brasil). Epidemiologia: a epidemiologia do câncer. Rio deJaneiro: IN CA; 1999.

2. American C ancer Society (US). Laryngeal and hypopharyngeal cancer. Philadelphia: ACS; 1999.

3. N oronhaM JR, D iasFL. Câncer delaringe: uma abordagem multidisciplinar. Rio de Janeiro: Revinter; 1997.

4. Zago M M F, Sawada N O , Stopa M J, M artinez EL. O significado deser laringectomizado. Rev Bras C ancerol 1998;44(2):139-45.

5. PriceB. Body image: nursing conceptsand care. London: PrenticeH all; 1990.

6. Ferreira $A B H$. N ovo dicionário da língua portuguesa. 2a ed. Rio de Janeiro: N ova Fronteira; 1986.

7. GambaA, Romano M, Grosso IM . Psychosocial adjustment of patientssurgically treated for head and neck cancer. $\mathrm{H}$ ead $\mathrm{N}$ eck 1992;14(3):218-23.

8. Siegel S. Estatística não-paramétrica para as ciências do comportamento. São Paulo:

M cG raw-Hill; 1975.

9. Behlau M S, Ziemer R. Reabilitação foniátrica do laringectomizado. In: Brandão LG , Ferraz AR. Cirurgia de cabeça e pescoço. São Paulo: Roca; 1989. p. 371-83.

10.G randa-C ameron $\mathrm{C}$. The experience of having cancer in Latin America. Cancer $\mathrm{N}$ urs

1999;22(1):51-7.

11.Schulze CM N. As representações sociais de pacientes portadores decâncer. In: Spink M J . O conhecimento no cotidiano: asrepresentações sociais na perspectiva da psicologia social. $2 a$ ed. São Paulo: Brasiliense; 1995. p. 267-79.

12.Pedrolo FT, Zago M M F. A imagem corporal alterada do laringectomizado: resignação com a condição. RevBrasCancerol 2000;46(4):407-15. 